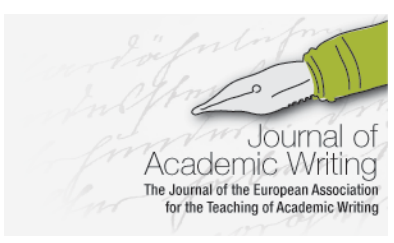

Journal of Academic Writing

Vol. 8 No 1 Summer 2018, pages 117-120 http://dx.doi.org/10.18552/joaw.v8i1.492

\title{
Review of Naming What We Know: Threshold Concepts of Writing Studies (Classroom Edition)
}

\author{
Páraic Kerrigan \\ Maynooth University, Ireland \\ Alison Farrell \\ Maynooth University, Ireland
}

\begin{abstract}
Adler-Kassner, Linda and Wardle, Elizabeth, eds. (2016) Naming What We Know: Threshold Concepts of Writing Studies. Logan: Utah State University Press, pp. 118, \$19.95 ISBN 978-1607325772
\end{abstract}

'As learners (and teachers and researchers), both of us have had learning experiences that have transformed us' (ix).

So begins Adler-Kassner and Wardle's preface to their edited collection Naming What We Know: Threshold Concepts of Writing Studies. With their opening statement, the editors make a professional connection across the areas of learning, teaching and researching. The interconnectedness, complementarity and essential synergistic nature of each of these key areas with writing infuses their edited collection. As such, it addresses a complex relationship across these four areas around which we believe there has been neglect, both in the literature on academic writing and writing studies, and in the higher education pedagogy and practice scholarship. As credible leaders in the field of writing studies, Adler-Kassner and Wardle's publication captures and curates what many of us think we know about writing, and indeed might easily recognize, but equally what we might have trouble defining. Using the framework of threshold concepts the work also addresses the dearth of 'frontier taxonomy' conversations around the areas of teaching, learning, research and writing (We ReLaTe 2018). In this regard, Adler-Kassner and Wardle bridge these four areas by identifying their collection as part of writing studies and, in tandem, prefacing the collection in teaching, learning and research not least through the use of threshold concepts.

The classroom edition of Naming What We Know is designed to provide 'a quick entry point to some of the often unstated beliefs about writing that [the] field has come to agree on after decades of research and theory' (xiii). Prior to presenting the thirty-six identified threshold concepts of writing studies, and drawing on the work of Meyer and Land (2006), the book begins with a brief sketching of threshold concepts, noting their troublesome nature, their inherent necessity for the negotiation of liminality, their integrative and transformative potential, and their probable irreversibility. The classroom edition of Naming What We Know has its origins in a longer version of the text which also includes eight essays 'that considered in more depth the ways in which these [threshold] concepts contributed to thinking and work in key points in the field' (xiii). In providing the desired 'entry point' the publication certainly achieves its goal and in doing so also opens up the field of writing studies to colleagues whose disciplinary expertise may have different but complementary foundations, not least among these being the world of higher education pedagogy and academic practice. Presenting the world of writing studies as threshold concepts provides a familiar framework or pattern for higher education colleagues who are encountering writing studies for the first time. As such, rather than writing studies being experienced as an alien discourse potentially inaccessible due to its foundation in unfamiliar scholarship, specifically rhetoric and composition, routing the uninitiated through threshold concepts allows colleagues with an interest in higher education teaching, learning and research to not only enter but to learn from, and about, writing studies. In this manner, a 
writing studies neophyte interacting with the book might be akin to a reader tackling a text written in one's own language albeit in a foreign dialect; with some engagement and curiosity, a common understanding can be identified and the text becomes decipherable.

With this publication Adler-Kassner and Wardle, and their contributing writing studies colleagues, intend to clearly state 'what [they] know and bring to the table' (7). In doing so they acknowledge that the book 'cannot represent the full set of threshold concepts' in the field, nor do they consider it 'possible or desirable to try to name, once and for all, all such concepts' (8). Rather the book is 'an effort to begin to name what we know' in the hope that the discussion will continue. As a starting point, therefore, the book presents its thirty-six threshold concepts, organized under five 'overarching' concepts and which are underpinned with one metaconcept. The metaconcept is that 'writing is an activity and a subject of study', that is, that writing is 'created, produced, distributed, and used for a variety of purposes' and that this activity provides 'areas of inquiry' (15). The five overarching concepts which are subsequently explored in the book are 'writing is a social and rhetorical activity', 'writing speaks to situations through recognizable forms', 'writing enacts and creates identities and ideologies', 'all writers have more to learn', and 'writing is (also always) a cognitive activity'. Each of these ideas is explored through a number of threshold concepts which are grouped appropriately under the relevant conceptual heading and which are written by writing studies colleagues with the collective experience and expertise of literally hundreds of years. As such, the collection is truly a collaboration from the field 'to attempt to collectively define threshold concepts of [the] discipline' (xii).

Beyond the achievement of producing a text based on offerings from such a broad sweep of authors (no mean feat as many serial collaborators will be aware), the contribution of this publication is captured succinctly by Kathy Blake Yancey in her introduction to the work. Blake Yancey notes that the collaborative statement of these threshold concepts serves as an 'articulation of shared beliefs providing multiple ways of helping us name what we know and how we can use what we know in the service of writing' (xix). It is the intention around naming and using, 'the use value', that tangibly connects the areas of teaching, learning, research and writing. Awareness and application of the threshold concepts of writing studies has the potential to illuminate and expand our teaching, learning, research and writing worlds and to see and exploit the synergies between them. Adler-Kassner and Wardle's collection provides what could be described as a theme and variations approach to the four areas. By turn, in our work each or any of the four areas could be the theme, an important and captivating tune in itself, but one which is illuminated and elaborated through its variations. These moves through the threshold concepts remind us that all four areas together in various arrangements can be 'knowledge-making', can 'create and recreate ... express and share meanings', can 'shape contexts and instruction', can 'involve making ethical choices', can work through 'recognizable forms', can 'represent the world, events, ideas and feelings', are 'a way of enacting disciplinarily', can create 'identities and ideologies', and are 'informed by prior experience'.

In practical terms, therefore, one of the benefits of this collection is that as colleagues working in higher education we can use it to help us in our orchestration of these four themes of our work. Taking the overarching threshold concept of 'all writers have more to learn' as an example, we can see how it can be of assistance to us in our various roles which are the professional enactment of the aforementioned four areas. Indeed, many of the processes that are emphasized in the threshold concepts under this heading are as relevant to teaching, learning and research as they are to writing. Just as Shirley Rose notes that 'all writers always have more to learn about writing' (59), equally we as teachers and researchers are also always learners. Indeed, many of the facets of this concept that 'all writers have more to learn' directly relate to the idea of ongoing development and how our processes must be subject to evaluation and subsequent reevaluation. Using the threshold concepts in this manner provides a helpful blueprint in guiding our writer, researcher, learner and teacher actions not least by acknowledging the liminality in each of these pursuits which in turn necessitates the 'two-stepsforward-one-step-back kind' of movement of contending with 'troublesome knowledge' (ix). Liminality exists in all four of these areas which we and our students encounter in higher education. Emphasizing process helps us to recognize that these areas are ever-changing and that our interaction with them is iterative. In turn, we acknowledge with Downs that writing, like 
teaching, research and learning is 'not in the category of things that are often right the first time' (66) and we are reassured that with practice, time and effort we can improve; as Blake Yancey notes, 'Through practice, we become familiar with writing; it becomes part of us. What we practice is who we are' (64). Collin Brooke and Allison Carr echo many of these ideas and are candid about another feature of writing which applies equally to teaching, learning and research, namely the role of failure. These writers observe that failure can offer 'an opportunity for growth' and accordingly, they suggest that we must treat 'failure as something all writers work through' (63).

In summary, Adler-Kassner and Wardle's collection encourages writers, teachers, learners and researchers to revisit and re-evaluate what we think we know about writing, not only in terms of our own approaches to writing, but also through a consideration of how we support our students and each other as writers. It is the sort of text that can be used to open up conversations with colleagues from a variety of disciplines through the numerous pedagogical insights that it provides. Similarly, as the vast majority of researchers need to be excellent writers, the articulation of threshold concepts of writing studies provides a much needed bridge between the traditionally oppositional focuses of teaching and learning, and research. Sharing in this particular conversation is a welcome contribution to the broader dialogue on the higher education experience and how some of its key elements might better complement each other. 


\section{References}

Blake Yancey, K. (2016) 'Introduction: Coming to Terms: Composition/Rhetoric, Threshold Concepts, and a Disciplinary Core'. in Naming What We Know. Threshold Concepts of Writing Studies (Classroom Edition). ed. by Adler-Kassner, L. and Wardle, E., Logan: Utah State University Press, xvii-xxxi

Blake Yancey, K. (2016) 'Learning to Write Effectively Requires Different Kinds of Practice, Time, and Effort'. in Naming What We Know. Threshold Concepts of Writing Studies (Classroom Edition). ed. by Adler-Kassner, L. and Wardle, E., Logan: Utah State University Press, 64-66

Brooke, C. and Carr, A. (2016) 'Failure Can Be an Important Part of Writing Development'. in Naming What We Know. Threshold Concepts of Writing Studies (Classroom Edition). ed. by Adler-Kassner, L. and Wardle, E., Logan: Utah State University Press, 62-64

Downs, D. (2016) 'Revision Is Central to Developing Writing'. in n Naming What We Know. Threshold Concepts of Writing Studies (Classroom Edition). ed. by Adler-Kassner, L. and Wardle, E., Logan: Utah State University Press, 66-67

Meyer, Jan H. F. and Land, R. (2006). 'Threshold Concepts and Troublesome Knowledge: An Introduction.' In Overcoming Barriers to Student Learning, ed. Meyer, J. H. F. and Land, R. London: Routledge, 3-18

Rose, S. (2016) 'All Writers Have More to Learn'. in Naming What We Know. Threshold Concepts of Writing Studies (Classroom Edition). ed. by Adler-Kassner, L. and Wardle, E., Logan: Utah State University Press, 59-61

We ReLaTe (2018) COST Action CA 15221: We ReLaTe. Advancing effective institutional models towards cohesive teaching, learning, research and writing development. [online] available from <http://www.werelate.eu> [26 January 2018] 